\title{
Inhibition of Wnt signaling by ICAT, a novel $\beta$-catenin-interacting protein
}

\author{
Ken-ichi Tago, ${ }^{1,2,5}$ Tsutomu Nakamura,, ${ }^{1,5}$ Michiru Nishita, ${ }^{3}$ Junko Hyodo, ${ }^{3}$ Shin-ichi Nagai, ${ }^{3}$ \\ Yoji Murata, ${ }^{1}$ Shungo Adachi, ${ }^{1}$ Susumu Ohwada, ${ }^{2}$ Yasuo Morishita, ${ }^{2}$ Hiroshi Shibuya, ${ }^{3}$ \\ and Tetsu Akiyama ${ }^{1,4,6}$ \\ ${ }^{1}$ Laboratory of Molecular and Genetic Information, Institute for Molecular and Cellular Biosciences, The University \\ of Tokyo, Bunkyo-ku, Tokyo 113, Japan; ${ }^{2}$ Second Department of Surgery, Gunma University School of Medicine, Maebashi, \\ Gunma 371, Japan; ${ }^{3}$ Division of Morphogenesis, Department of Developmental Biology, National Institute for Basic Biology, \\ Okazaki 444, Japan; ${ }^{4}$ Department of Oncogene Research, Institute for Microbial Diseases, Osaka University, Suita, \\ Osaka 565, Japan
}

Wnt signaling has an important role in both embryonic development and tumorigenesis. $\beta$-Catenin, a key component of the Wnt signaling pathway, interacts with the TCF/LEF family of transcription factors and activates transcription of $\mathrm{Wnt}$ target genes. Here, we identify a novel $\beta$-catenin-interacting protein, ICAT, that was found to inhibit the interaction of $\beta$-catenin with TCF-4 and represses $\beta$-catenin-TCF-4-mediated transactivation. Furthermore, ICAT inhibited Xenopus axis formation by interfering with Wnt signaling. These results suggest that ICAT negatively regulates Wnt signaling via inhibition of the interaction between $\beta$-catenin and TCF and is integral in development and cell proliferation.

[Key Words: Wnt; $\beta$-catenin; TCF; ICAT; signaling]

Received Feburary 28, 2000; revised version accepted May 24, 2000.

The Wnt/Wingless signaling transduction pathway is involved in many developmental processes via the regulation of Wnt-responsive genes (Miller and Moon 1996; Cadigan and Nusse 1997; Clevers and van de Wetering 1997; Bienz 1998; Eastman and Grosschedl 1999). Expression of these genes is regulated by the TCF/LEF family of transcription factors, whose activity is promoted by their association with $\beta$-catenin (Behrens et al. 1996; Molenaar et al. 1996; Brunner et al. 1997; Riese et al. 1997; van de Wetering et al. 1997; Hsu et al. 1998; Galceran et al. 1999). The stability of $\beta$-catenin is in turn determined by its association with Axin, glycogen synthase kinase- $3 \beta$ (GSK-3 $\beta$ ), and the tumor suppressor adenomatous polyposis coli (APC) (Munemitsu et al. 1995; Behrens et al. 1998; Hart et al. 1998; Ikeda et al. 1998; Itoh et al. 1998; Nakamura et al. 1998; Sakanaka et al. 1998; Hamada et al. 1999; Willert et al. 1999), the mutation of which is responsible for familial adenomatous polyposis (FAP) and sporadic colorectal tumors (Kinzler and Vogelstein 1996; Polakis 1997; Bienz 1999|. Wnt signaling promotes the stabilization of $\beta$-catenin by negatively regulating the activity of GSK-3$\beta$. Intact APC normally induces the degradation of $\beta$-catenin, but the mutant APCs found in most colon cancers are defective in this activity. Furthermore, of those tumors that contain

\footnotetext{
${ }^{5}$ These authors contributed equally to the work.

${ }^{6}$ Corresponding author.

E-MAIL akiyama@imcbns.iam.u-tokyo.ac.jp; FAX 81358418482.
}

intact APC, many have stabilizing mutations in $\beta$-catenin itself (Morin et al. 1997; Rubinfeld et al. 1997). Therefore, regulation of $\beta$-catenin stability and, consequently, $\beta$-catenin-TCF/LEF-mediated transactivation are critical for Wnt signaling during development and tumorigenesis. In this study we show that a novel $\beta$-catenin-interacting protein, termed ICAT (inhibitor of $\beta$-catenin and TCF-4), interferes with the interaction between $\beta$-catenin and TCF-4 and antagonizes Wnt signaling.

\section{Results and Discussion}

In an attempt to identify $\beta$-catenin-interacting proteins, we performed a yeast two-hybrid screen of a mouse embryo cDNA library using the Armadillo repeat domain of $\beta$-catenin as bait and found a new protein, ICAT. Sequence analysis of the ICAT cDNA showed that it encodes a protein of 81 amino acids with no homology to other known proteins (Fig. 1A). Highly conserved orthologs were identified as EST clones from human, rat, and zebrafish, and Xenopus ICAT was isolated from a Xenopus oocyte library. Northern blot analysis detected an mRNA of $2.6 \mathrm{~kb}$, which is expressed at high levels in mouse heart, brain, liver, and skeletal muscle, at low levels in kidney, testis, and lung, and at undetectable levels in spleen (data not shown). ICAT mRNA was expressed at fairly constant levels during development of the mouse embryo (data not shown).

To confirm that ICAT and $\beta$-catenin interact directly, we examined the ability of ICAT fused to glutathione 
Tago et al.

A

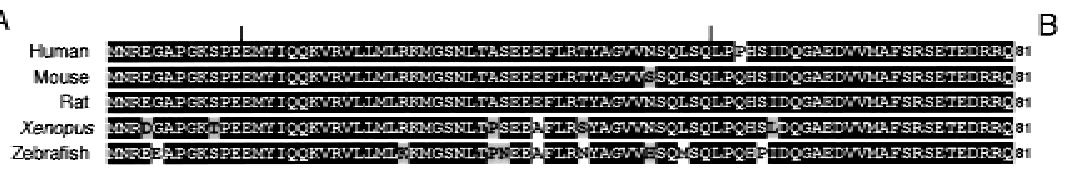

B

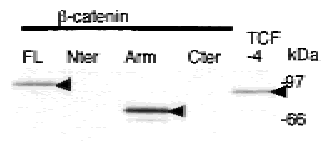

Input

$-46$

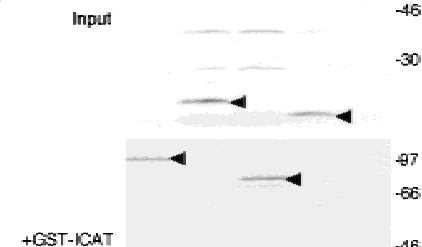

C

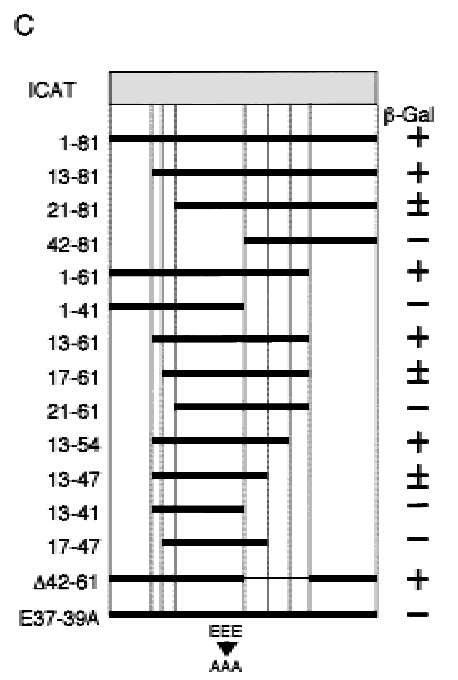

B-Catenin
Armadilo repeat

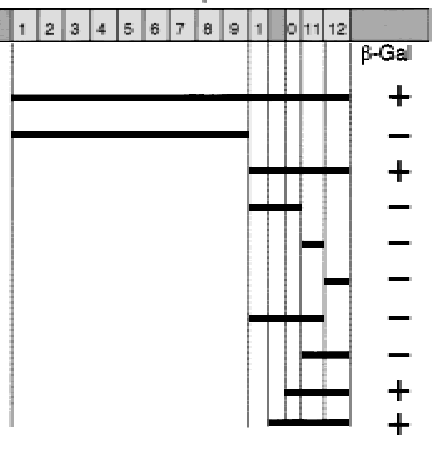

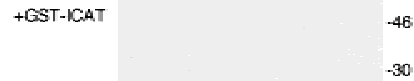

D

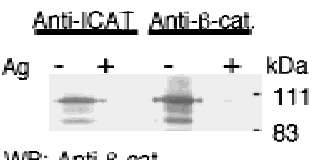

WB: Anti-p-cat.

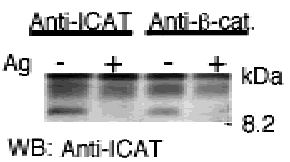

Figure 1. Association of ICAT with $\beta$-catenin. (A) Predicted amino acid sequences of ICATs. Identical and similar residues are highlighted in black and gray, respectively. Vertical bars indicate the region critical for binding to $\beta$-catenin (see $C$ ). (B) Association of ICAT with $\beta$-catenin in vitro. In vitro-translated ${ }^{35}$ S-labeled proteins indicated (Input) were incubated with GST-ICAT-Sepharose (+GST-ICAT). The bound proteins were analyzed by SDS-PAGE. (C) Mapping of regions in ICAT and $\beta$-catenin required for interaction. Deletion constructs of ICAT (left) or $\beta$-catenin (right) were analyzed for their ability to interact with GAL4- $\beta$-catenin or GAL4-ICAT, respectively, in the two-hybrid system. $(+)$ Detectable activity; $( \pm)$ marginal activity; $(-)$ no detectable activity. $(D)$ Association of ICAT with $\beta$-catenin in vivo. Lysates prepared from mouse brain were subjected to immunoprecipitation with the antibodies indicated, fractionated by SDS-PAGE, and immunoblotted with the antibodies indicated. (Ag+) Antibodies were preincubated with antigen before use in immunoprecipitation.

S-transferase (GST) to interact with $\beta$-catenin produced by in vitro translation. GST-ICAT, but not GST alone, associated with in vitro-translated $\beta$-catenin (Fig. 1B). Two-hybrid assays using various deletion fragments of ICAT revealed that the central region of ICAT is involved in the interaction with $\beta$-catenin (Fig. 1C). It has been reported that the $\beta$-catenin binding regions of cadherins, APC, and TCF family members are all acidic (Huber et al. 1997). Therefore, we generated a mutant ICAT-E37-39A, in which Glu-37, Glu-38, and Glu-39 were all replaced with Ala and found that this mutant is negative for interaction with $\beta$-catenin (Fig. 1C). On the other hand, the minimal region of $\beta$-catenin required for binding to ICAT was found to reside in the fragment spanning from the carboxy-terminal portion of repeat 10 to repeat 12 (Fig. 1C). In contrast, Armadillo repeats 1-9 did not exhibit any affinity to ICAT.

Next, we examined whether ICAT is associated with $\beta$-catenin in vivo. For this purpose, we generated antibodies to the carboxy-terminal portion of ICAT and con- firmed that the antibodies react specifically with GSTICAT (data not shown). When a lysate from mouse brain was subjected to immunoprecipitation and subsequent immunoblotting with anti-ICAT antibodies, we detected a $9-\mathrm{kD}$ protein, and precipitation of this protein was inhibited by preincubation of the antibodies with antigen (Fig. 1D). In addition, a protein of the same mobility was expressed prominently when COS-7 cells were transfected with ICAT cDNA (data not shown). These results suggest that ICAT gene product is a $9-\mathrm{kD}$ protein. Then we subjected a lysate from mouse brain to immunoprecipitation with anti-ICAT antibodies and immunoblotted the precipitates with anti- $\beta$-catenin antibody. ICAT was found to coprecipitate with $\beta$-catenin, and coprecipitation was inhibited by preincubation of anti-ICAT antibodies with antigen (Fig. 1D). Also, immunoprecipitation of the lysate with anti- $\beta$-catenin antibody, followed by immunoblotting with anti-ICAT antibodies, revealed an association between ICAT and $\beta$-catenin. Preincubation of the anti- $\beta$-catenin antibody with the antigen pre- 
vented coprecipitation of $\beta$-catenin and ICAT. These results suggest that ICAT is associated with $\beta$-catenin in living cells. On the other hand, ICAT-E37-39A ectopically expressed in COS-7 cells failed to coprecipitate with $\beta$-catenin (data not shown). Consistent with these results, ICAT was found to colocalize with $\beta$-catenin in the nucleus of the human colorectal tumor cell line SW480 (data not shown). ICAT was also detected in the cytoplasm and nucleus of mouse colon epithelial cells. ICAT colocalized with $\beta$-catenin in the cytoplasm but not at the plasma membrane in the epithelial cells of the colon.

The TCF family of proteins is known to form a complex with $\beta$-catenin that binds to specific DNA sequences and transactivates target genes (Behrens et al. 1996; Molenaar et al. 1996; Brunner et al. 1997; Riese et al. 1997; van de Wetering et al. 1997; Hsu et al. 1998; Galceran et al. 1999). Therefore, we asked whether ICAT affects the DNA-binding properties of the $\beta$-cateninTCF-4 complex. As reported previously (Korinek et al. 1997), an electrophoretic mobility-shift assay (EMSA) showed that $\beta$-catenin produced by the baculovirus system and TCF-4 generated by in vitro translation bound to an oligonucleotide containing a TCF-4-binding site as a ternary complex (Fig. 2A). However, when in vitrotranslated TCF- 4 and $\beta$-catenin were preincubated with GST-ICAT, this ternary complex was not detected. Instead, a band migrating with the mobility of the TCF-4DNA complex was detected. Addition of anti-TCF-4 antibodies, but not anti- $\beta$-catenin and/or anti-ICAT antibodies, induced supershift of this band, suggesting that the band represents the TCF-4-DNA complex. In a par-

A
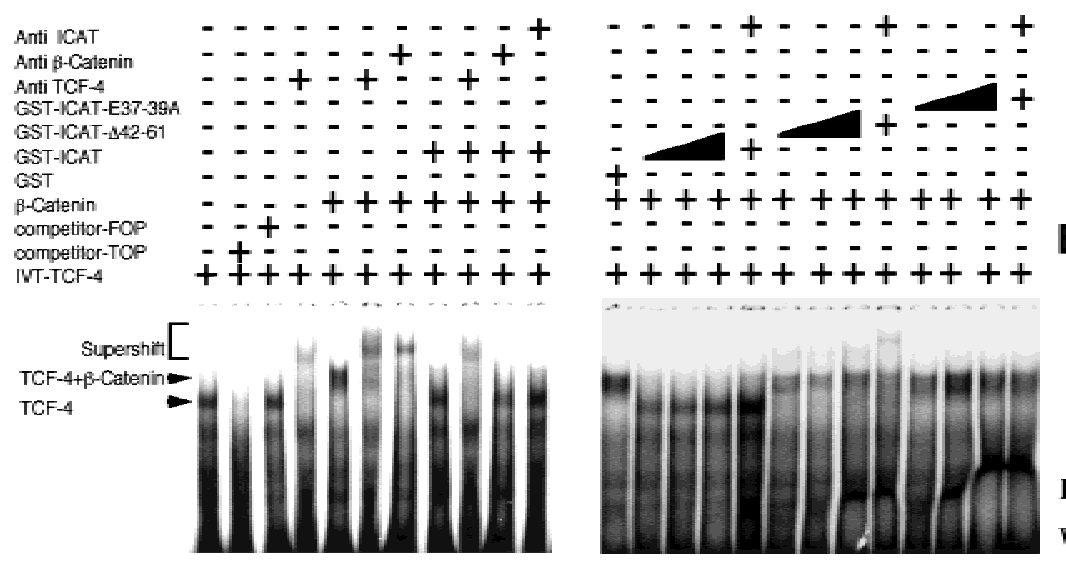

\section{B}
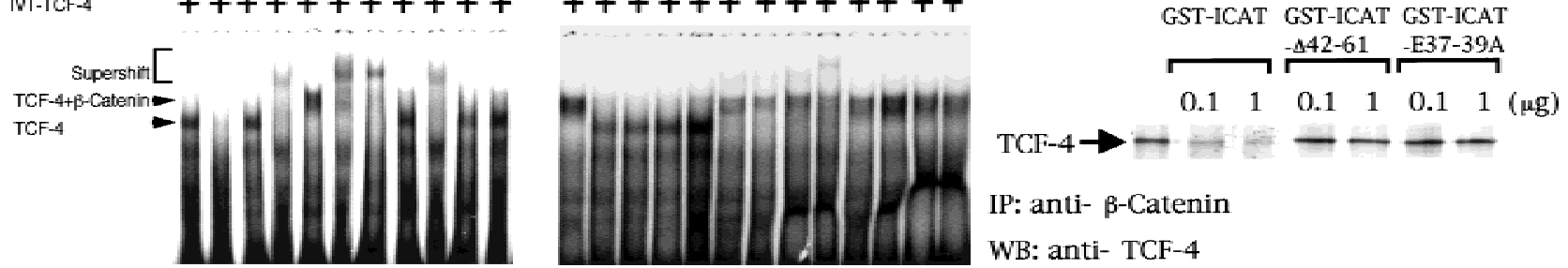

IP: anti- $\beta$-Catenin

WB: anti- TCF-4
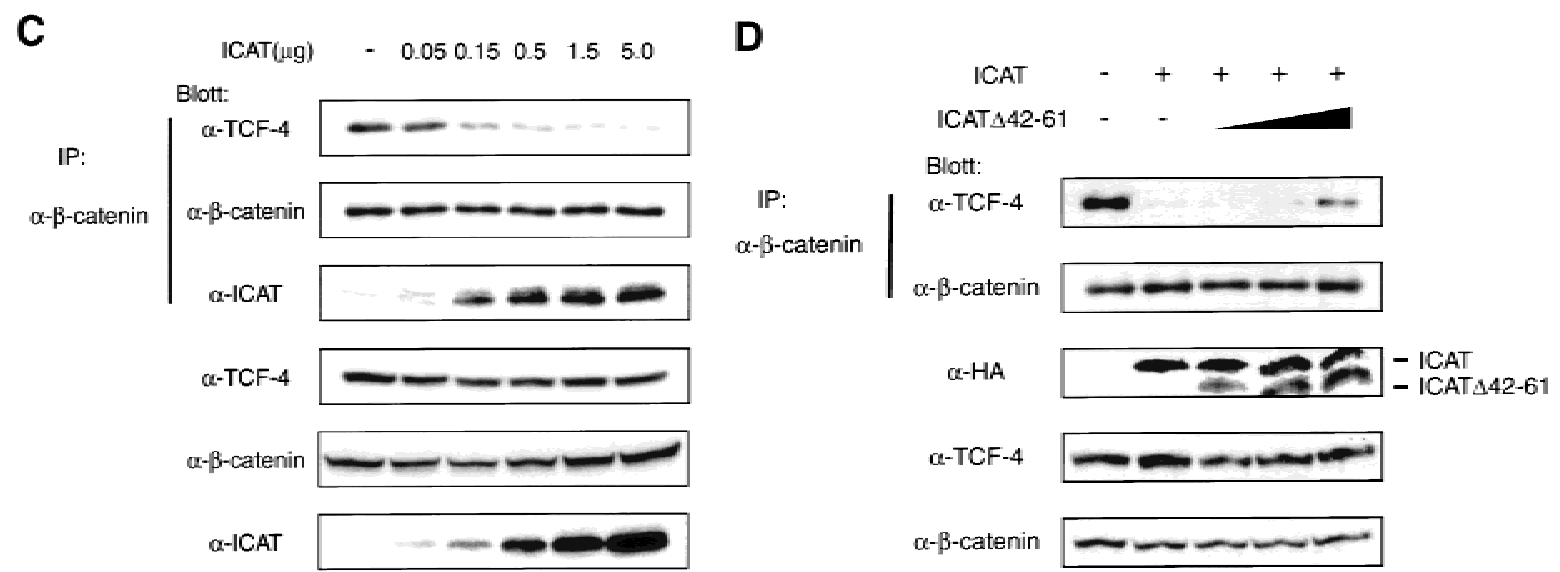

Figure 2. ICAT inhibits the formation of the $\beta$-catenin-TCF-4 complex. (A) The $\beta$-catenin-TCF-4-DNA complex is not detected in the presence of ICAT. An oligonucleotide containing a potential binding site for TCF-4 was incubated with in vitro-translated TCF-4, $\beta$-catenin produced by the baculovirus system, and GST-ICAT as indicated. DNA-protein interactions were analyzed by EMSAs. Unlabeled oligonucleotides containing either consensus (competitor-TOP) or mutated (competitor-FOP) sites were used as competitors in some reactions. $(B)$ ICAT inhibits the interaction between $\beta$-catenin and TCF-4 in vitro. $\beta$-Catenin (3 ng) and TCF-4 (10 ng) produced by the baculovirus system were incubated in the presence of $100 \mathrm{ng}$ or $1 \mu \mathrm{g}$ of GST-ICAT, GST-ICAT-E37-39A, or GST-ICAT- $\Delta 42-61$, respectively. $\beta$-Catenin was immunoprecipitated with anti- $\beta$-catenin antibody, and the immunoprecipitates were subjected to immunoblotting analysis with anti-TCF- 4 antibodies. (C) ICAT inhibits the interaction between $\beta$-catenin and TCF-4 in vivo. $\beta$-catenin and TCF-4 were transfected along with ICAT into human kidney epithelial 293 cells. $\beta$-Catenin was immunoprecipitated with anti- $\beta$-catenin antibody, and the immunoprecipitates were subjected to immunoblotting analysis with antibodies indicated. $(D)$ ICAT- $\Delta 42-61$ abrogates the inhibitory effect of wild-type ICAT on the interaction between $\beta$-catenin and TCF-4. HA-tagged ICAT- $\beta 42-61$ was transfected along with HA-tagged ICAT, $\beta$-catenin, and TCF-4 into 293 cells. $\beta$-Catenin was immunoprecipitated, and coprecipitating TCF-4 was detected by immunoblotting with anti-TCF-4 antibodies. 
allel pull-down experiment, we found that the amounts of TCF-4 that coimmunoprecipitated with anti- $\beta$ catenin decreased in a dose-dependent manner with increasing amounts of ICAT (Fig. 2B). Furthermore, when $\beta$-catenin and TCF-4 were transfected along with ICAT into human kidney epithelial 293 cells, the amounts of TCF-4 coimmunoprecipitating with $\beta$-catenin also decreased as the expressed amount of ICAT increased (Fig. $2 \mathrm{C})$. These results suggest that ICAT interferes with the formation of the $\beta$-catenin-TCF- 4 complex. In addition, ICAT was also found to interfere with the interaction between $\beta$-catenin and Xenopus TCF-3 (data not shown). On the other hand, the mutant ICAT-E37-39A did not inhibit the interaction between $\beta$-catenin and TCF-4 (Fig. 2B) and had no effect on the formation of a $\beta$-catenin-TCF-4-DNA complex (Fig. 2A).

Next we examined the effect of ICAT on $\beta$-cateninTCF-regulated transcription. In colon carcinoma cells, $\beta$-catenin-TCF-regulated transcription is constitutively activated because of loss of APC function or activation of $\beta$-catenin (Korinek et al. 1997; Morin et al. 1997). Therefore, we transfected ICAT into the human colon cancer cell lines DLD-1 and SW48, along with a reporter plasmid that contains optimal TCF-binding sites upstream of a luciferase reporter gene. DLD-1 contains mutated APC and wild-type $\beta$-catenin, whereas SW48 possesses wild-type APC and mutated $\beta$-catenin. ICAT repressed the activity of the reporter gene in both cell lines in a dose-dependent manner (Fig. 3A). In contrast, ICATE37-39A failed to inhibit reporter activity. In these experiments, ICAT and ICAT-E37-39A were expressed at similar levels (Fig. 3A, insets). We also examined the effect of ICAT on Wnt-1-induced transactivation of the reporter plasmid using 293 cells. Expression of Wnt-1 greatly enhanced the activity of the reporter gene, but coexpression of ICAT with Wnt-1 strongly repressed its activity (Fig. 3B). We also found that ICAT inhibits ectopic $\beta$-catenin-induced activation of the reporter gene (Fig. 3C). These results suggest that ICAT represses $\beta$-catenin-TCF-4-mediated transcription by interfering with the interaction between $\beta$-catenin and TCF-4.

To further examine the physiological significance of ICAT, we tried to generate a dominant-negative mutant of ICAT. We examined the effects of several deletion mutant ICATs (shown in Fig. 1C) on $\beta$-catenin-TCF-4mediated transcription and found that ICAT- $442-61$, which encodes a mutant lacking amino acids 42-61, alleviates the inhibitory effect of wild-type ICAT on $\beta$-catenin-mediated transactivation of the reporter gene (Fig. 3C). Although ICAT- $442-61$ was able to interact with $\beta$-catenin (Fig. 1C), it did not interfere with the interaction between $\beta$-catenin and TCF-4 (Fig. 2B) and exhibited very little inhibition of the $\beta$-catenin-TCF-4 complex DNA-binding activity (Fig. 2A). Furthermore, ICAT- $-42-61$ abrogated the inhibitory effect of wildtype ICAT on the interaction between $\beta$-catenin and TCF-4 (Fig. 2D). Collectively, these results suggest that ICAT $-\Delta 42-61$ acts as a dominant-negative mutant, presumably by competing with ICAT for binding to $\beta$-catenin. Interestingly, ICAT- $442-61$ activated tran- scription of the reporter gene in a dose-dependent manner (Fig. 3C), suggesting that endogenous ICAT normally has an important role in repressing endogenous $\beta$-catenin-TCF-mediated transcription in cultured cells.

It is well established that the Wnt pathway has a crucial role in the development of the Xenopus embryonic axis, and injection of mRNA encoding various components of the Wnt pathway into Xenopus embryos is known to affect embryonic axis formation (Miller and Moon 1996; Cadigan and Nusse 1997; Clevers and van de Wetering 1997; Bienz 1998; Eastman and Grosschedl 1999). When ICAT mRNA synthesized in vitro was injected into the dorsal marginal zone of four-cell embryos, embryos became significantly ventralized [average $\mathrm{DAI}=2.8, n=30$ (Fig. 4A)]. On the other hand, injection of ICAT mRNA into the ventral side had no effect on embryo development (data not shown). Injection of ICAT mRNA near the dorsal midline of four-cell embryos led to a reduction in the expression of dorsal marker genes Siamois and Goosecoid in dorsal marginal zone explants relative to explants isolated from uninjected embryos (Fig. 4B). In contrast, injection of ICAT mRNA induced expression of ventral and posterior mesoderm markers Xvent-1 and Xhox-3, respectively (Fig. 4B).

Then we examined the effects of dominant-negative mutant ICAT- 442-61 on embryonic axis formation. When ICAT- 4 42-61 was injected into the dorsal side, embryos were not ventralized. However, ICAT- $442-61$ acted as a potent dorsalizer when injected into the ventral side of four-cell embryos, producing secondary axes in $90 \%$ of them (Fig. 4C). Also, ventral injection of ICAT-442-61 induced expression of the dorsal marker and reduced expression of the ventral markers (Fig. 4D). Furthermore, this effect of ICAT- $42-61$ was abrogated by coinjection of wild-type ICAT (Fig. 4E). Together with the results obtained in vitro (Figs. 1C, 2A,B,D, and 3C,D), ICAT- $-42-61$ is thought to act as a dominant-negative mutant by competing with endogenous Xenopus ICAT for binding to $\beta$-catenin and activate $\beta$-catenin-TCF-4mediated transactivation. These findings suggest that endogenous Xenopus ICAT has an important role during the development of Xenopus embryos. On the other hand, ICAT-E37-39A showed no effect on embryo development and did not induce any reduction in dorsal marker gene expression (data not shown), suggesting that the $\beta$-catenin-binding activity of ICAT is required for its function.

To test whether ICAT might exert its effects via the Wnt pathway, we coinjected mRNA encoding $X W n t-8$, $\beta$-catenin, Siamois, or Twin, together with ICAT mRNA, into the ventral side of four-cell embryos. Siamois and Twin are homeobox genes whose expression is specifically activated by Wnt signaling and appear to mediate the effects of the Wnt pathway on axis formation (Brannon et al. 1997; Laurent et al. 1997; Fan et al. 1998). Coinjection of ICAT inhibited the induction of the axis and dorsal marker Goosecoid by $\beta$-catenin but did not affect secondary axis formation or Goosecoid expression induced by Siamois or Twin (Fig. 4F,G). ICAT also in- 


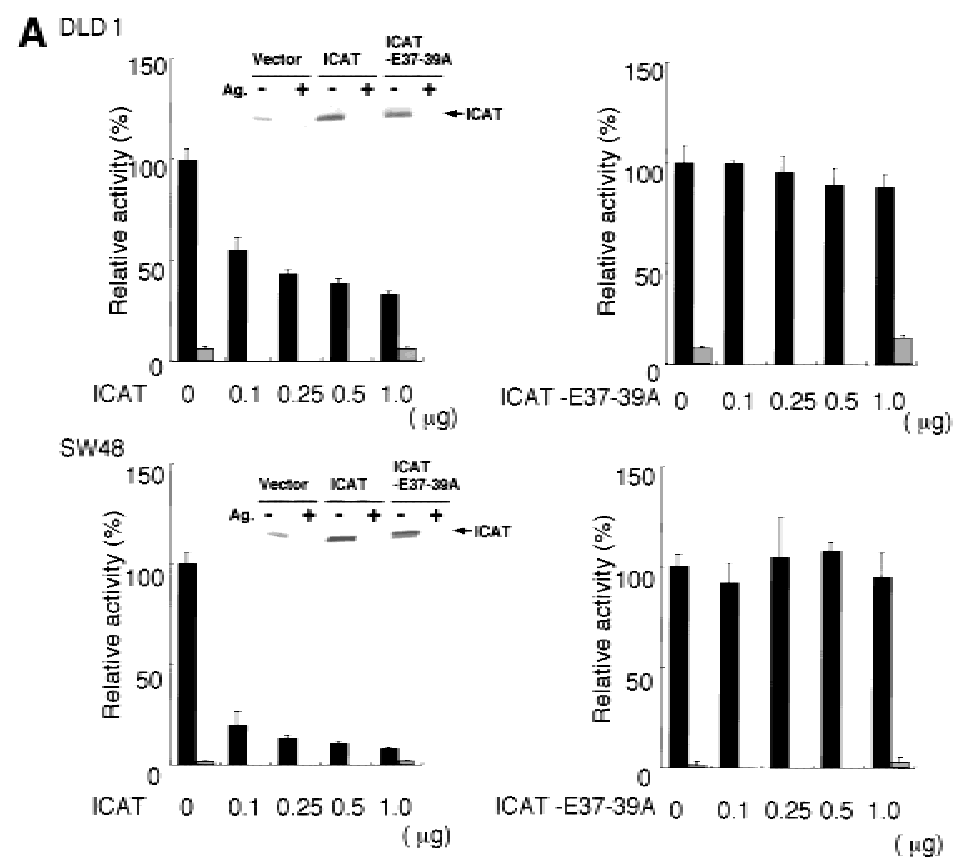

B

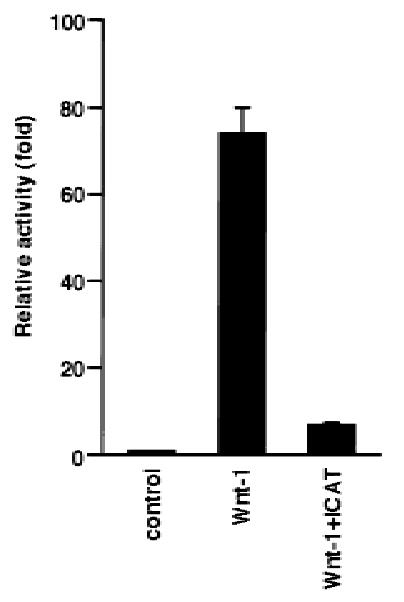

C

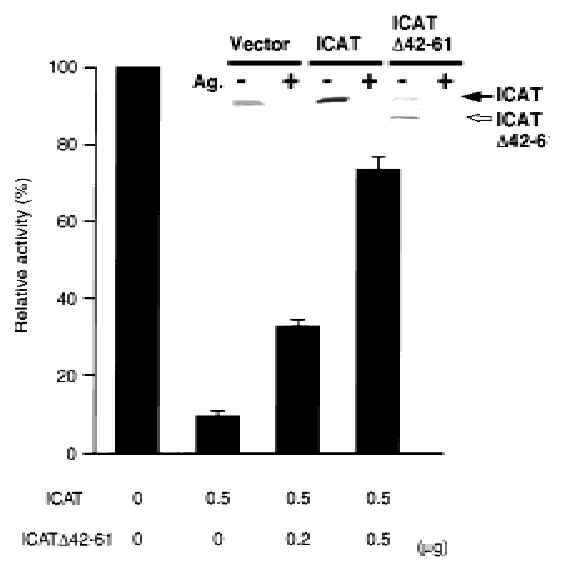

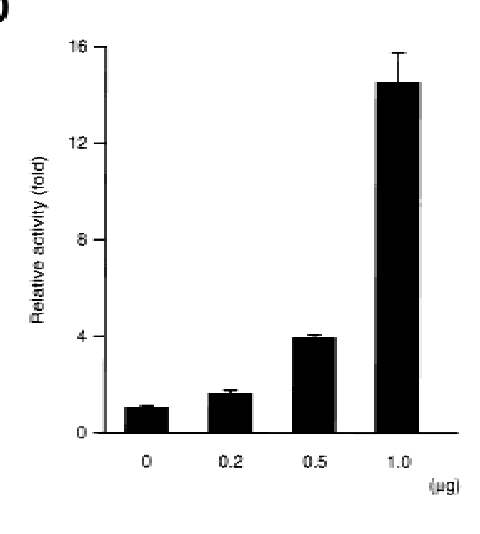

Figure 3. Effect of ICAT on $\beta$-catenin-TCFregulated transcription. (A) ICAT represses constitutively activated $\beta$-catenin-TCF-mediated transcription in colorectal cancer cells. The human colorectal cancer cell lines DLD-1 and SW48 were transfected with the luciferase reporter plasmid TOPtkLuciferase (solid bars) or FOPtkLuciferase (shaded bars), and increasing amounts of ICAT, ICATE37-39A, and luciferase activity were measured (15). TOPtkLuciferase contains optimal and FOPtkLuciferase contains mutated TCF-binding sites placed upstream of a luciferase reporter gene. Luciferase activities are expressed relative to samples containing no ICAT and ICAT-E37-39A. (Insets) Detection of endogenous ICAT and exogenously expressed ICAT and ICAT-E37-39A (indicated by closed arrow). Lysates prepared from DLD-1 or SQ48 cells transfected with the indicated plasmids $(1.0 \mu \mathrm{g})$ were subjected to immunoprecipitation and subsequent immunoblotting with anti-ICAT antibodies. $(\mathrm{Ag}+)$ Antibodies were preincubated with antigen before use in immunnoprecipitation. (B) ICAT represses Wnt-1-induced $\beta$-catenin-TCF-mediated transactivation. 293 cells were transfected with luciferase reporter plasmids, ICAT, and Wnt-1, and luciferase activity was measured. (C) ICAT- $442-$ 61 abrogates the inhibitory effect of wildtype ICAT on $\beta$-catenin-TCF-mediated transcription. 293 cells were transfected with the luciferase reporter $(0.05 \mu \mathrm{g})$, $\beta$-catenin $(0.01 \mu \mathrm{g}), I C A T$, and ICAT- $442-$ 61 , as indicated. (Inset) Detection of endogenous ICAT, exogenously expressed ICAT (indicated by solid arrow), and ICAT- $\Delta 42-61$ (open arrow). Lysates prepared from 293 cells transfected with the indicated plasmids $(0.5$ $\mu \mathrm{g}$ ) were subjected to immunoprecipitation and subsequent immunoblotting with antiICAT antibodies. (Ag+) Antibodies were preincubated with antigen before use in immunoprecipitation. (D) ICAT- $442-61$ activates endogeneous $\beta$-catenin-TCF-mediated transcription. 293 cells were transfected with the luciferase reproter $(0.05 \mu \mathrm{g})$ and increasing amounts of ICAT- $442-61$ (as indicated). hibited Wnt-8-induced axis duplication (Fig. 4F). Thus, ICAT appears to exert its effect by interfering with signaling through the Wnt pathway at a point downstream of $\beta$-catenin, and upstream of Siamois and Twin. In addition, we found that ICAT failed to block the induction of the secondary axis caused by ventral injection of 
Tago et al.

Figure 4. Effects of ICAT on axis formation in Xenopus embryos. (A) Dorsal injection of ICAT-induced ventralization of Xenopus embryos. Synthetic ICAT mRNA (2 ng) was injected into each of two dorsal blastomeres at the four-cell stage and phenotypes were evaluated at the tadpole stage. $(B)$ Dorsal injection of ICAT reduced expression of the dorsal markers Goosecoid and Siamois and induced expression of the ventral markers Xhox-3 and Xvent-1. DMZ fragments injected with ICAT mRNA ( $2 \mathrm{ng}$ ) were cultured until gastrula stage 11 , and total RNA was analyzed by RT-PCR for the presence of the indicated transcripts: (lane 1) Whole embryo; (lane 2) uninjected; (lane 3) ICAT (2 ng); (lane 4) RT. Histone was used as a loading control. (C) Ventral injection of ICAT- $442-61$ mRNA $(500 \mathrm{pg})$ induced ectopic axis formation in Xenopus embryos. (D) Ventral injection of ICAT- $442-61$ induced expression of the dorsal marker and reduced expression of the ventral markers. VMZ fragments injected with ICAT- $442-61$ mRNA 1500 pg) were analyzed as described in $B$. (Lane 1) Whole embryo; (lane 2) uninjected; (lane 3) ICAT- 442-61 (500 pg); (lane 4) RT. (E) ICAT- $442-61$-induced ectopic axis formation in Xenopus embryos was not observed when wild-type ICAT was coinjected with ICATS42-61. (F) (Left) Ventral coinjection of ICAT mRNA inhibits ectopic axis formation by $\beta$-catenin but not by downstream targets (Siamois and Twin) of the Wnt pathway, or by Noggin or $\triangle B M P R-I A$. mRNA encoding the indicated dorsalizing factor was injected into two ventral blastomeres at the four-cell stage with or without $2 \mathrm{ng}$ of ICAT, and embryos were examined for axial duplications at the tadpole stage. The fraction of embryos with duplicated axes is indicated above each bar. mRNAs were injected in the minimal amounts needed to induce ectopic axes at high frequency: $(5 \mathrm{pg})$ Siamois; $(5 \mathrm{pg})$ Twin; (1 pg) Noggin; or (50 pg) $\triangle B M P R-I A$. (Right) ICAT (2 ng) also inhibits Wnt-8 (10 pg)-induced axis duplication. When ICAT plus $\beta$-catenin plus Wnt- 8 were expressed, ICAT did not exhibit a strong effect. This may be because the amounts of $\beta$-catenin in cells overexpressing both exogenous $\beta$-catenin and Wnt- 8 were higher than that of ICAT. $(G)$ Coinjection of ICAT mRNA inhibits induction of the dorsal marker Goosecoid by $\beta$-catenin but not by Siamois or Twin. Synthetic mRNAs containing the indicated DNA sequences were injected into the equatorial region of blastomeres at the two-cell stage. Animal caps coinjected with $\beta$-catenin (200 pg), Siamois (5 pg), or Twin $(5 \mathrm{pg})$, with or without ICAT (2 ng) mRNA, were cultured until the gastrula stage, and total RNA was analyzed by RT-PCR for the presence of the indicated transcripts: (Lane 1) Whole embryo; (lane 2) uninjected; (lane 3) ICAT; (lane 4) $\beta$-catenin; (lane 5) $\beta$-catenin and ICAT; (lane 6) Siamois; (lane 7) Siamois and ICAT; (lane 8) Twin; (lane 9) Twin and ICAT; (lane 10) RT.

mRNA encoding Noggin, a natural inhibitor of BMPs or a dominant-negative truncated BMP receptor ( $\beta B M P R$ IA; Fig. 4F). Thus, ICAT is thought to act as a negative regulator specifically on the Wnt signaling pathway.

When cells are stimulated with the Wnt signal,
A

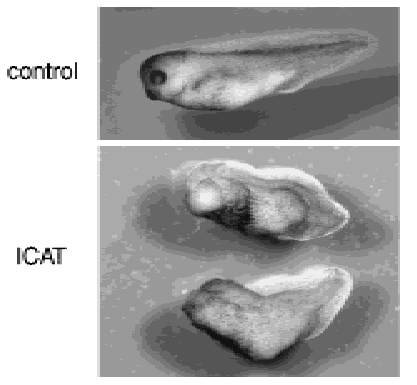

B

Goosecoid ${ }^{1} \mathrm{H}^{3} \mathrm{H}^{4}$
Siamois
Xhox-3
Xvent-1
Histone

C
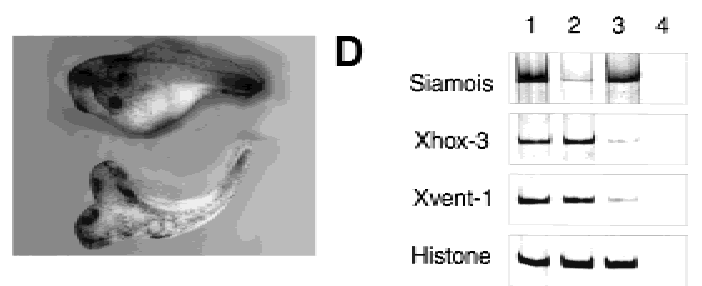

E

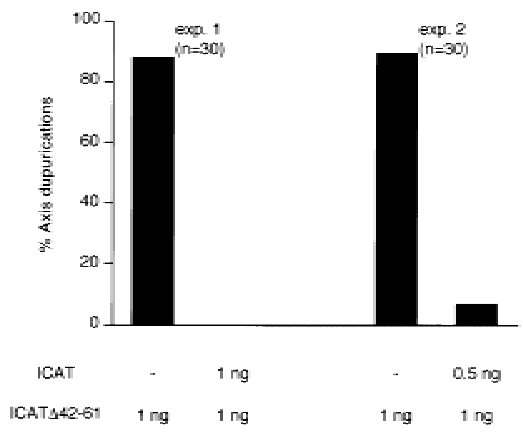

$\mathbf{F}$
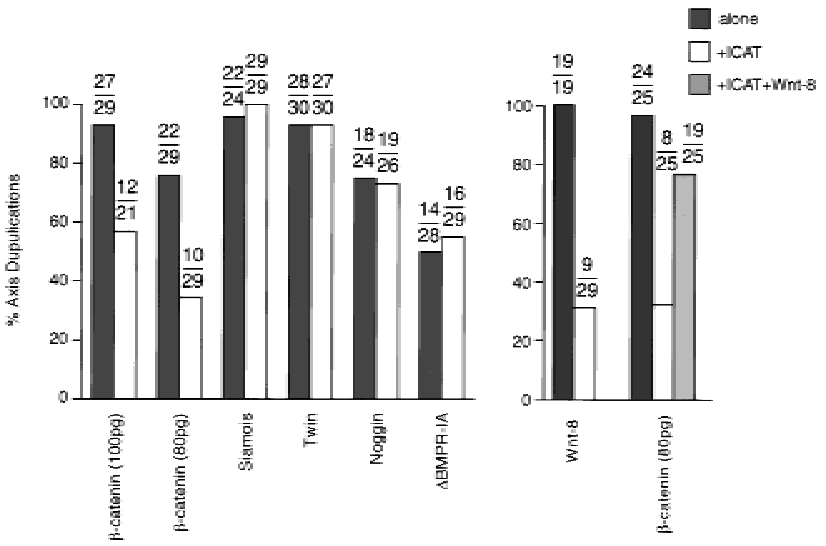

G

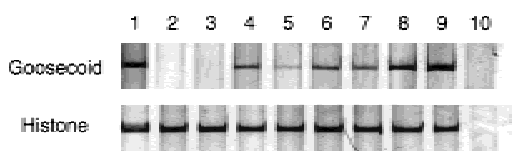

$\beta$-catenin is stabilized and accumulates within the cell (Miller and Moon 1996; Cadigan and Nusse 1997; Clevers and van de Wetering 1997; Bienz 1998; Eastman and Grosschedl 1999), whereas ICAT levels do not change significantly (data not shown). Thus, the amount of 
$\beta$-catenin not associated with ICAT may increase, leading to transcriptional activation. The importance of ICAT in vivo was confirmed by experiments using Xenopus embryos, which suggested that ICAT has an important role in negatively regulating the Wnt signaling pathway in Xenopus development. We found that Xenopus ICAT (XICAT) transcripts are expressed maternally and throughout development from the egg to the tailbud stage, with a decline in expression during gastrulation, and that XICAT coprecipitates with $\beta$-catenin from a lysate prepared from Xenopus embryos (stage 10.5) (data not shown). XICAT transcripts are expressed ubiquitously and are not localized to any specific region in the early gastrula stage. However, XICAT transcripts become localized to the nervous system at the end of neurulation and are restricted to the central nervous system, eye, and head neural crest cell populations by the tadpole stages. These expression patterns are consistent with its putative function in developmental processes, including dorsoventral axis formation. Although it is well known that endogenous $\beta$-catenin is enriched in the dorsal, compared to the ventral, regions, there is a certain amount of $\beta$-catenin present in ventral regions (Larabell et al. 1997). We speculate that $\beta$-catenin in the ventral regions is associated with ICAT, and the amount of free active $\beta$-catenin is insufficient to induce transactivation in the absence of a Wnt signal. Consistent with this notion, ventral expression of the dominant-negative mutant ICAT- $-42-61$ induced axis duplication, presumably by competing with endogenous ICAT for binding to $\beta$-catenin. The amount of active $\beta$-catenin generated by the action of ICAT- $\Delta 42-61$ may be enough to induce transcriptional activation in Xenopus embryos. Taken together, we speculate that ICAT may function to establish a threshold to prevent premature and inappropriate signaling events. On the other hand, it has been reported recently that in the absence of $\beta$-catenin, TCF is associated with members of the Groucho family of proteins and acts as a transcriptional repressor of Wnt/Wingless target genes (Cavallo et al. 1998; Roose et al. 1998). Thus, the function of $\beta$-catenin may be regulated by the balance among ICAT, $\beta$-catenin, and the Groucho family of proteins.

Constitutive activation of $\beta$-catenin-TCF-mediated transcription due to inactivation of the tumor suppressor APC or gain-of function mutations in $\beta$-catenin is thought to be important in colorectal tumorigenesis (Kinzler and Vogelstein 1996; Korinek et al. 1997; Morin et al. 1997; Polakis 1997; Rubinfeld et al. 1997; Bienz 1999). Because ICAT is a negative regulator of Wnt signaling, its inactivation could also induce inappropriate activation of the transcription. It is therefore interesting to speculate that ICAT may function as a tumor suppressor and its inactivation may lead to tumorigenesis. Given its function in inhibiting $\beta$-catenin-TCF-mediated transcription, ICAT may be of interest as a gene therapy agent. Drugs that mimic the effects of ICAT may be useful as antitumor reagents as well, and elucidation of the three-dimensional structure of ICAT may provide insights into the development of such drugs.

\section{Materials and methods}

Two-hybrid system

Two-hybrid experiments were performed as described (Hamada et al. 1999) using the Armadillo domain of mouse $\beta$-catenin (amino acids 128-683) as bait (The GenBank accession number of ICAT is $\mathrm{AB021261.)}$

In vitro binding assays

${ }^{35}$ S-Labeled proteins were synthesized by in vitro transcription translation in the presence of $\left[{ }^{35} \mathrm{~S}\right]$ methionine using the TNTcoupled reticulocyte lysate system (Promega). GST fusion proteins immobilized to glutathione-Sepharose were mixed with in vitro-translated proteins in buffer A $(10 \mathrm{~mm}$ Tris $-\mathrm{HCl}$ at $\mathrm{pH}$ 8.0, $140 \mathrm{~mm} \mathrm{NaCl}, 1 \mathrm{~mm}$ EDTA, $10 \mu \mathrm{g} / \mathrm{ml}$ leupeptin, $10 \mu \mathrm{g} / \mathrm{ml}$ aprotinin) containing $0.1 \%$ Triton X-100 for $2 \mathrm{hr}$ at $4^{\circ} \mathrm{C}$ and then washed extensively with buffer A.

\section{Antibodies}

Antibodies to ICAT were prepared by immunizing rabbits with a peptide containing amino acids $70-81$ of ICAT. Antibodies to TCF-4E were generated with a peptide corresponding to the carboxy-terminal 20 amino acids of TCF-4E. Mouse monoclonal antibody to $\beta$-catenin was purchased from Transduction Laboratories. GST- $\beta$-catenin was used to block anti- $\beta$-catenin antibody.

\section{Immunoprecipitation and immunoblotting}

Immunoprecipitation and immunoblotting were performed as described previously (Matsumine et al. 1996). To examine the effect of ICAT on the interaction between $\beta$-catenin and TCF- 4 in vitro, $\beta$-catenin $(3 \mathrm{ng}$ ) and TCF-4 (10 ng) produced by the baculovirus system were incubated in $150 \mu \mathrm{l}$ of buffer A for $1 \mathrm{hr}$ at $4^{\circ} \mathrm{C}$ in the presence of $100 \mathrm{ng}$ or $1 \mu \mathrm{g}$ of GST-ICAT, GSTICAT-E37-39A, or GST-ICAT- $\Delta 42-61$, respectively. $\beta$-Catenin was immunoprecipitated with anti- $\beta$-catenin antibody and protein G-Sepharose, and the immunoprecipitates were subjected to immunoblotting analysis with anti-TCF-4 antibodies.

\section{EMSAs}

As the optimal TCF probe, we used a double-stranded 26nucleotide oligomer containing a potential TCF/LEF binding site derived from TOPtkLuciferase reporter (Korinek et al. 1997). The mutant probe was derived from FOPtkLuciferase reporter. In vitro-translated TCF-4, $\beta$-catenin produced by the baculovirus system $(0.1 \mu \mathrm{g})$ and GST-ICAT $(0.1,0.3$, or $1 \mu \mathrm{g})$ were incubated for $2 \mathrm{hr}$ in binding buffer (10 mM Tris at $\mathrm{pH} 7.5$, $1 \mathrm{~mm}$ EDTA, $60 \mathrm{~mm} \mathrm{KCl}$, 12\% glycerol, $1.0 \mathrm{~mm}$ DTT, $1.5 \mu \mathrm{g}$ BSA) in a total volume of $30 \mu \mathrm{l}$. Probe $(6.8 \mathrm{ng})$ end-labeled to $7.6 \times 10^{6} \mathrm{cpm} / \mu \mathrm{g}$, poly[d(I-C)] $(1 \mu \mathrm{g})$ and herring sperm DNA (1.5 $\mu \mathrm{g}$ ) were added and incubated for an additional $20 \mathrm{~min}$. Competition analyses were performed with an excess amount $(680$ ng) of unlabeled probe.

\section{Luciferase assays}

Cells $\left(6 \times 10^{5}\right.$ cells $/ 60-\mathrm{mm}$ dish) were transfected by Lipofectamine with a total of $4 \mu \mathrm{g}$ of the various combinations of plasmids: $0.5 \mu \mathrm{g}$ of reporter plasmid (TOPtkLuciferase or FOPtkLuciferase); $0.05 \mu \mathrm{g}$ of internal control pRL-TK (Promega); the indicated amount of wild-type and/or mutant ICAT expression vector (pMKITNeoICAT), and empty pMKITNeo vector as 
Tago et al.

stuffer. Luciferase activities were measured $24 \mathrm{hr}$ after transfection using the Dual-Luciferase Reporter Assay System (Promega).

\section{Embryo manipulations}

ICAT, ICAT- 442-61, and ICAT-E37-39A cDNAs were cloned into the pCS2+ vector (Rupp et al. 1994). RNAs were then injected into the animal poles or marginal zones of early-stage embryos as described (Moon and Christian 1989). Dorsal marginal zone (DMZ) assay, ventral marginal zone (VMZ) assay, and animal cap assay were performed as described (Shibuya et al. 1998). Total RNA was then extracted and analyzed with RTPCR as described (Wilson and Melton 1994; Wilson and Hemmati-Brivanlou 1995).

\section{Acknowledgments}

We thank N. Ueno and T. Ishidate for discussion and encouragement. We also thank V. Korinek and H. Clevers for TOPtkLuciferase and FOPtkLuciferase. This work was supported by Grants-in-Aid for Scientific Research on Priority Areas and the Organization for Pharmaceutical Safety and Research.

The publication costs of this article were defrayed in part by payment of page charges. This article must therefore be hereby marked "advertisement" in accordance with 18 USC section 1734 solely to indicate this fact.

\section{References}

Behrens, J., von Kries, J.P., Kuhl, M., Bruhn, L., Wedlich, D., Grosschedl, R., and Birchmeier, W. 1996. Functional interaction of $\beta$-catenin with the transcription factor LEF-1. Nature 382: 638-642.

Behrens, J., Jerchow, B.A., Wurtele, M., Grimm, J., Asbrand, C., Wirtz, R., Kuhl, M., Wedlich, D., and Birchmeier, W. 1998. Functional interaction of an axin homolog, conductin, with $\beta$-catenin, APC, and GSK3 $\beta$. Science 280: 596-599.

Bienz, M. 1998. TCF: Transcriptional activator or repressor? Curr. Opin. Cell Biol. 10: 366-372.

- 1999. APC: The plot thickens. Curr. Opin. Genet. Dev. 9: 595-603.

Brannon, M., Gomperts, M., Sumoy, L., Moon, R.T., and Kimelman, D. 1997. A $\beta$-catenin/XTcf-3 complex binds to the Siamois promoter to regulate dorsal axis specification in Xenopus. Genes \& Dev. 11: 2359-2370.

Brunner, E., Peter, O., Schweizer, L., and Basler, K. 1997. pangolin encodes a Lef-1 homologue that acts downstream of Armadillo to transduce the Wingless signal in Drosophila. $\mathrm{Na}$ ture 385: 829-833.

Cadigan, K.M. and Nusse, R. 1997. Wnt signaling: A common theme in animal development. Genes \& Dev. 11:32863305.

Cavallo, R.A., Cox, R.T., Moline, M.M., Roose, J., Polevoy, G.A., Clevers, H., Peifer, M., and Bejsovec, A. 1998. Drosophila Tcf and Groucho interact to repress Wingless signalling activity. Nature 395: 604-608.

Clevers, H. and van de Wetering, M. 1997. TCF/LEF factor earn their wings. Trends Genet. 13: 485-489.

Eastman, Q. and Grosschedl, R. 1999. Regulation of LEF-1/TCF transcription factors by Wnt and other signals. Curr. Opin. Cell Biol. 11: 233-240.

Fan, M.J., Gruning, W., Walz, G., and Sokol, S.Y. 1998. Wnt signaling and transcription control of Siamois in Xenopus embryo. Proc. Nat1. Acad. Sci. 95: 5626-5631.

Galceran, J., Farinas, I., Depew, M.J., Clevers, H., and Grosschedl, R. 1999. Wnt3a $\mathrm{a}^{-/-}$-like phenotype and limb deficiency in Lef1 $1^{-/-} \mathrm{Tcf1}^{-/-}$mice. Genes \& Dev. 13: 709-717.

Hamada, F., Tomoyasu, Y., Takatsu, Y., Nakamura, M., Nagai, S., Suzuki, A., Fujita, F., Shibuya, H., Toyoshima, K., Ueno, N., et al. 1999. Negative regulation of Wingless signaling by D-axin, a Drosophila homolog of axin. Science 283: 17391742.

Hart, M.J., de los Santos, R., Albert, I.N., Rubinfeld, B., and Polakis, P. 1998. Downregulation of $\beta$-catenin by human Axin and its association with the APC tumor suppressor, $\beta$-catenin and GSK3 $\beta$. Curr Biol. 8: 573-581.

Hsu, S.C., Galceran, J., and Grosschedl, R. 1998. Modulation of transcriptional regulation by LEF-1 in response to Wnt-1 signaling and association with $\beta$-catenin. Mol. Cell. Biol. 18: 4807-4818.

Huber, A.H., Nelson, W.J., and Weis, W.I. 1997. Three-dimensional structure of the armadillo repeat region of $\beta$-catenin. Cell 90: 871-882.

Ikeda, S., Kishida, S., Yamamoto, H., Murai, H., Koyama, S., and Kikuchi, A. 1998. Axin, a negative regulator of the Wnt signaling pathway, forms a complex with GSK-3 $\beta$ and $\beta$-catenin and promotes GSK-3 $\beta$-dependent phosphorylation of $\beta$-catenin. EMBO J. 17: 1371-1384.

Itoh, K., Krupnik, V.E., and Sokol, S.Y. 1998. Axis determination in Xenopus involves biochemical interactions of axin, glycogen synthase kinase 3 and $\beta$-catenin. Curr. Biol. 8: 591594.

Kinzler, K.W. and Vogelstein, B. 1996. Lessons from hereditary colorectal cancer. Cell 87: 159-170.

Korinek, V., Barker, N., Morin, P.J., van Wichen, D., de Weger, R., Kinzler, K.W., Vogelstein, B., and Clevers, H. 1997. Constitutive transcriptional activation by a $\beta$-catenin-Tcf complex in APC-/- colon carcinoma. Science 275: 1784-1787.

Larabell, C.A., Torres, M., Rowning, B.A., Yost, C., Miller, J.R., Wu, M., Kimelman, D., and Moon, R.T. 1997. Establishment of the dorso-ventral axis in Xenopus embryos is presaged by early asymmetries in $\beta$-catenin that are modulated by the Wnt signaling pathway. J. Cell Biol. 136: 1123-1136.

Laurent, M.N., Blitz, I.L., Hashimoto, C., Rothbacher, U., and Cho, K.W.-Y. 1997. The Xenopus gene Twin mediates Wnt induction of Goosecoid in establishment of Spemann's organizer. Development 124: 4905-4916.

Matsumine, A., Ogai, A., Senda, T., Okumura, N., Satoh, K. Baeg, G.H., Kawahara, T., Kobayashi, S., Okada, M., Toyoshima, K., and Akiyama, T. 1996. Binding of APC to the human homolog of the Drosophila discs large tumor suppressor protein. Science 272: 1020-1023.

Miller, J.R. and Moon, R.T. 1996. Signal transduction through $\beta$-catenin and specification of cell fate during embryogenesis. Genes \& Dev. 10: 2527-2539.

Molenaar, M., van de Wetering, M., Oosterwegel, M., PetersonMaduro, J., Godsave, S., Korinek, V., Roose, J., Destree, O., and Clevers, H. 1996. XTcf-3 transcription factor mediates $\beta$-catenin-induced axis formation in Xenopus embryos. Cell 86: 391-399.

Moon, R.T. and Christian, J.L. 1989. Microinjection and expression of synthetic mRNAs in Xenopus embryos. Technique 1: 76-89.

Morin, P.J., Sparks, A.B., Korinek, V., Barker, N., Clevers, H., Vogelstein, B., and Kinzler, K.W. 1997. Activation of $\beta$-catenin-Tcf signaling in colon cancer by mutations in $\beta$-catenin or APC. Science 275: 1787-1790.

Munemitsu, S., Albert, I., Souza, B., Rubinfeld, B., and Polakis, P. 1995. Regulation of intracellular $\beta$-catenin levels by the 
adenomatous polyposis coli (APC) tumor-suppressor protein. Proc. Natl. Acad. Sci. 92: 3046-3050.

Nakamura, T., Hamada, F., Ishidate, T., Anai, K., Kawahara, K., Toyoshima, K., and Akiyama, T. 1998. Axin, an inhibitor of the Wnt signalling pathway, interacts with $\beta$-catenin, GSK$3 \beta$ and APC and reduces the $\beta$-catenin level. Genes Cells 3: 395-403.

Polakis, P. 1997. The adenomatous polyposis coli (APC) tumor suppressor. Biochim. Biophys. Acta 1332: F127-F147.

Riese, J., Yu, X., Munnerlyn, A., Eresh, S., Hsu, S.C., Grosschedl, R., and Bienz, M. 1997. LEF-1, a nuclear factor coordinating signaling inputs from wingless and decapentaplegic. Cell 88: 777-787.

Roose, J., Molenaar, M., Peterson, J., Hurenkamp, J., Brantjes, H., Moerer, P., van de Wetering, M., Destree, O., and Clevers, H. 1998. The Xenopus Wnt effector XTcf-3 interacts with Groucho-related transcriptional repressors. Nature 395: 608-612.

Rubinfeld, B., Robbins, P., El-Gamil, M., Albert, I., Porfiri, E., and Polakis, P. 1997. Stabilization of $\beta$-catenin by genetic defects in melanoma cell lines. Science 275: 1790-1792.

Rupp, R.A., Snider, L., and Weintraub, H. 1994. Xenopus embryos regulate the nuclear localization of XMyoD. Genes \& Dev. 8: 1311-1323.

Sakanaka, C., Weiss, J.B., and Williams, L.T. 1998. Bridging of $\beta$-catenin and glycogen synthase kinase- $3 \beta$ by axin and inhibition of $\beta$-catenin-mediated transcription. Proc. Natl. Acad. Sci. 95: 3020-3023.

Shibuya, H., Iwata, H., Masuyama, N., Gotoh, Y., Yamaguchi, K., Irie, K., Matsumoto, K., Nishida, E., and Ueno, N. 1998. Role of TAK1 and TAB1 in BMP signaling in early Xenopus development. EMBO J. 17: 1019-1028.

van de Wetering, M., Cavallo, R., Dooijes, D., van Beest, M., van Es, J., Loureiro, J., Ypma, A., Hursh, D., Jones, T., Bejsovec, A. et al. 1997. Armadillo coactivates transcription driven by the product of the Drosophila segment polarity gene dTCF. Cell 88: 789-799.

Willert, K., Logan, C.Y., Arora, A., Fish, M., and Nusse, R. 1999. A Drosophila Axin homolog, Daxin, inhibits Wnt signaling. Development 126: 4165-4173.

Wilson, P.A. and Hemmati-Brivanlou, A. 1995. Induction of epidermis and inhibition of neural fate by Bmp-4. Nature 376: 331-333.

Wilson, P.A. and Melton, D.A. 1994. Mesodermal patterning by an inducer gradient depends on secondary cell-cell communication. Curr. Biol. 4: 676-686. 


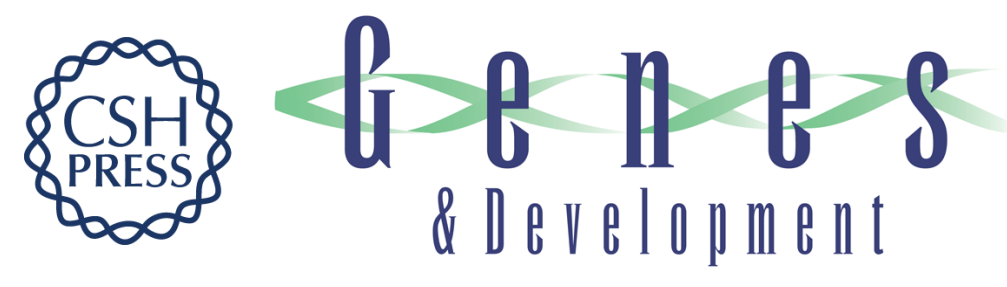

\section{Inhibition of Wnt signaling by ICAT, a novel $\beta$-catenin-interacting protein}

Ken-ichi Tago, Tsutomu Nakamura, Michiru Nishita, et al.

Genes Dev. 2000, 14:

Access the most recent version at doi:10.1101/gad.14.14.1741

References This article cites 40 articles, 20 of which can be accessed free at: http://genesdev.cshlp.org/content/14/14/1741.full.html\#ref-list-1

License

Email Alerting

Receive free email alerts when new articles cite this article - sign up in the box at the top Service right corner of the article or click here.

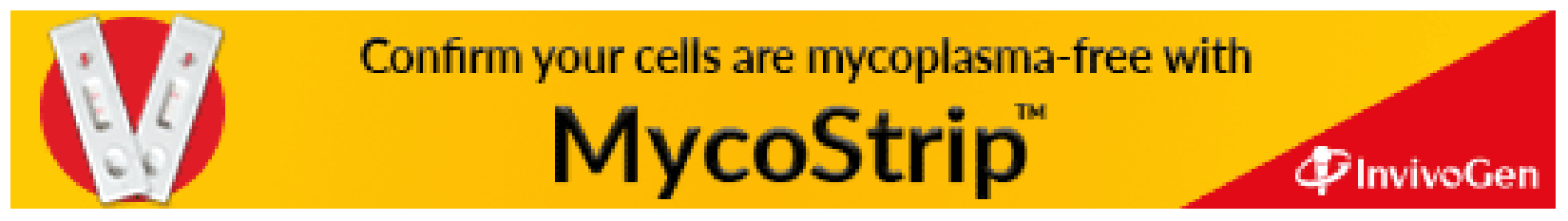

